\title{
PONTIS: AN OPTIMIZATION SYSTEM FOR IMPROVING AND MAINTAINING BRIDGE NETWORKS IN THE U.S.A.
}

\author{
Kamal Golabi, Optima Inc., U.S.A.
}

This paper presents a recently completed network optimization system to address the improvement and maintenance of bridge networks. The federally-funded bridge management system has sufficient flexibility for implementation in various states replacing current procedures which are largely based on subjective sufficiency ratings. The system would not only provide each agency with a decision tool to help in planning for MR\&R (maintenance, repair and rehabilitation), improvement and replacement of its bridges, but would also provide a common basis for allocation of resources to states by federal agencies according to improvement needs and bridge conditions of each state.

The system, developed under the direction of the speaker, is named Pontis and addresses the dynamic, multiobjective bridge $M R \& R$ and improvement problem through a set of interrelated predictive, optimization and economic models. The system integrates the objectives of public safety and risk reduction, user convenience, and preservation of investment, with budgetary and program policies, and it effectively provides a vehicle for comparing preventive versus corrective maintenance policies. It gives a systematic procedure for allocation of resources to the improvement and MR\&R of various bridges in the network and considers the costs and benefits of maintenance policies versus investments in improvement or replacement. Furthermore, it specifies minimum funding requirements to remove backlogs and achieve goals, and predicts future network conditions for various budget scenarios.

Pontis has been implemented in California and has undergone extensive tests in several other states. It is planned that the system would serve as a basis for bridge management decisions in all states. 